\title{
Application of Multichannel Analysis of Surface Waves to S-Phase Wave Anisotropy Estimation
}

\author{
Iwona STAN-KŁECZEK and Maciej J. MENDECKI \\ University of Silesia, Faculty of Earth Sciences, Sosnowiec, Poland \\ e-mails: iwona.stan-kleczek@us.edu.pl,mmendecki@us.edu.pl
}

\begin{abstract}
The Multichannel Analysis of Surface Waves (MASW) is an increasingly used technique for recognition of a shallow geological structure and estimation of geotechnical parameters, e.g., $S$-wave velocity, layer density, layer thickness, shear modulus, estimated $P$-wave velocity, and estimated Poisson ratio. MASW surveys were carried out in two limestone quarries in the southern part of Poland. The experimental areas are characterised by a simple geological structure: consolidated Triassic limestone. Measurement profiles were arranged as a shapely six-pointed star. For each survey line, 12 geophones with 2-meter (Deposit 1) and 3-meter (Deposit 2) spacing were applied. The research allowed to compare $P$ - and $S$-wave velocity changes with the main crack systems in the studied rock masses.
\end{abstract}

Key words: surface waves, Rayleigh waves dispersion curve, MASW, genetic algorithm, $S$-waves anisotropy.

\section{INTRODUCTION}

Cracks are very common features of the rock mass which have influence on physical properties of rocks. Cracks make the rock much more susceptible to mechanical effects. The main consequence of the existence of cracks for the elastic wave propagation is the development of seismic anisotropy due to the

Ownership: Institute of Geophysics, Polish Academy of Sciences;

(C) 2016 Stan-Kłeczek and Mendecki. This is an open access article distributed under

the Creative Commons Attribution-NonCommercial-NoDerivs license,

http://creativecommons.org/licenses/by-nc-nd/3.0/. 
anisotropic distribution of crack orientation. Numerous theoretical and experimental papers describe the relationship between fracture parameters and seismic wave velocity (e.g., Anderson et al. 1974, Barton 2007, StanKłeczek 2008, Vilhelm et al. 2011, Dobróka et al. 2012) and also relations between elastic properties and crack systems (Živor et al. 2011, StanKłeczek and Idziak 2008, Bukowska et al. 2007, Bukowska and Sanetra 2008, Jarzyna et al. 2010). The seismic anisotropy studies usually use $P$ wave velocity less often than $S$-wave velocity. The Multichannel Analysis of Surface Waves (MASW) method is a non-invasive method recently developed to estimate a shear wave velocity. It allows an identification of $S$ waves from a packet of surface waves of Rayleigh type, its analysis and at the same time a solution of different other problems (Çaylak and Kaftan 2014, Polkowski and Grad 2015). The characteristic of Rayleigh waves is related to its element, that is, a vertical shear wave $S V$. The parameters of Rayleigh waves, like velocity, are directly dependent on elastic properties of rock mass. The aim of the presented studies is to identify the possibility of using the Multichannel Analysis of Surface Waves (MASW) to study the anisotropy of carbonate rock masses.

\section{STUDY AREA CHARACTERISATION}

The study area is located in the southern part of Poland in two Triassic limestone quarries.

\subsection{Deposit 1 - Strzelce Opolskie}

The first deposit is the Triassic limestone (Fig. 1).

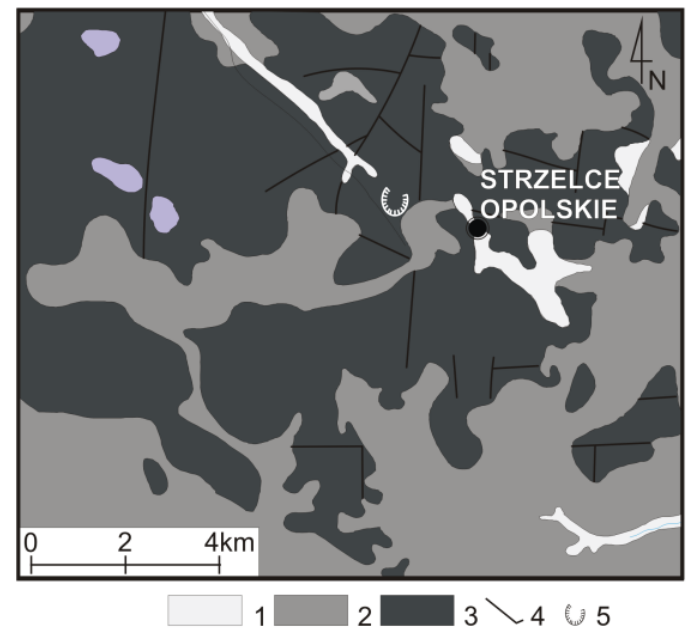

Fig. 1. The geological structure of Deposit 1: 1 - Holocene, 2 - Neogene, 3 - Triassic, 4 - main faults, 5 - the Strzelce Opolskie quarry. 
The studied rock mass is located in the borough of Strzelce Opolskie, about $30 \mathrm{~km}$ from Opole. In the Strzelce Opolskie deposit there occurs a complete profile of the Lower Muschelkalk. The layers were deposited one upon the other, falling in towards the north at an angle of $2-4^{\circ}$. The Triassic layers consist of different types of limestone. The Triassic rock series are covered by the Neogene sediments like sandstone and boulder clay (Czarakcziewa 1971).

\subsection{Deposit 2 - Sadowa Góra}

The second deposit built of Triassic limestone is called Sadowa Góra (Fig. 2). It is situated on the south-west limb of Wilkoszyn Syncline which is located in the south-east part of the Upper Silesia Basin. The thickness of the Triassic sequence ranges from about 1 to $200 \mathrm{~m}$ (Stan-Kłeczek et al. 2012). This pit is characterised by limestones, marls, cellular limestones, interbed limestone conglomerates, undulated limestones, and ore-bearing dolomites in the roof part of the quarry.

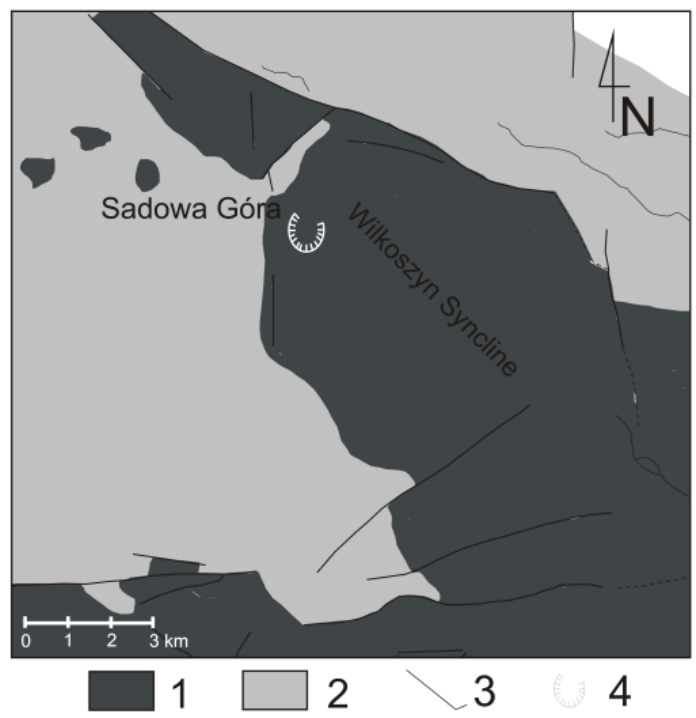

Fig. 2. The geological structure of Deposit 2: 1 - Triassic, 2 - Carboniferous, 3 main faults, 4 - the Sadowa Góra quarry.

\section{PRINCIPLES OF MASW}

At the beginning of the 1980s, spectral analysis of surface waves (SASW), which produced the near surface $S$-waves profiles, was introduced (Nazarian et al. 1983). SASW, as other seismic methods, carried out spectral analysis of surface waves generated by an artificial source and registered by a pair of geophones. Next, the 
data were proceeded in the frequency domain to obtain a dispersion curve. However, this method was time consuming and ineffective in the long term. The multichannel analysis of surface waves (MASW) attempted to overpass the ineffectiveness of the spectral analysis of the surface wave method (Nazarian et al. 1983, Park et al. 1999).

\subsection{Rayleigh wave dispersion}

Rayleigh surface waves, propagating along a free surface, such as the earthair interface, are oriented and dispersive. Particle motion of the Rayleigh wave fundamental mode is elliptical in a retrograde direction, if waves are moving from left to right. As a result of wave propagation in the dispersion medium (layered medium), surface waves with different frequencies propagate at different velocities. This means that the velocity of the corresponding signal, called group velocity, is different from the propagation velocity of the phase velocity, and also depends on the frequency, leading to the dispersion of the seismic signal (Park et al. 1999, Xia et al. 1999, Foti et al. 2011).

It is known that a simple, two-dimensional slowness-frequency $(p-f)$ transform of recorded seismic traces allows to distinguish Rayleigh waves from other seismic arrivals (Louie 2001, Foti et al. 2011). The $p-f$ transformation takes a fragment of seismic traces $(x-t)$ and converts it to the ray parameter $p$ and an intercept time $\tau$ (Louie 2001). This transform is a line integral across a seismic record $A(x, t)$ at distance $x$ and time $t$ (Louie 2001)

$$
A(p, \tau)=\int_{x} A(x, t=\tau+p x) d x
$$

where the slope of the line $p=d t / d x$ is the inverse of the apparent velocity $V_{a}$ in the $x$ direction. Next, complex Fourier transform $F_{A}(p, f)$ in the intercept time direction is computed for the each $p-\tau$ trace in $A(p, \tau)$. They consist of 24 slowness traces, which are the sum across a registration at all intercept times, at a single slowness or velocity value (Louie 2001):

$$
F_{1}(p, f)=\int_{\tau} A(p, \tau) e^{-2 \pi f \tau} d x .
$$

Then the power spectrum $S_{A}(p, f)$ as the magnitude squared of the complex Fourier transform is calculated (Louie 2001):

$$
S_{A}(p, f)=F_{A}^{*}(p, f) F_{A}(p, f)
$$

where $*$ denotes the complex conjugate. Two $p$ - $\tau$ transforms are summed together in both forward and reverse directions along the receiver line. Finally, the slowness-frequency analysis allows to obtain the total spectral power in all records from a survey profile where a coherent phase has significant power. This procedure is used to find dispersion curves of Rayleigh waves of normal modes in low velocity surface layers (Louie 2001). 


\section{2 $S$-waves profiling}

Dispersion is a common property used in surface wave methods. Shear wave velocity $\left(V_{s}\right)$ can be calculated by mathematical inversion of the dispersive phase velocity of surface waves. Surface wave dispersion can be significant in the presence of velocity layering, which is common in the near-surface environment. There are other types of surface waves, or waves that travel along a surface, but in this application we are concerned with the Rayleigh wave, which is also called "ground roll" since the Rayleigh wave is the dominant component of ground roll.

Before the inversion procedure, forward modeling must be carried out to create an initial $V_{s}$ model based on observed data. To avoid local minima in the inversion that often generate unreal velocity changes with depth, the interactive modeling must be applied (Lai and Rix 1998, Xia et al. 1999, Louie 2001, Dal Moro et al. 2007).

Genetic Algorithms (GAs) have been proposed to find the best inverse solution and thus the appropriate $V_{s}$ model. The problem defines an environment ( $S$-wave velocities and thicknesses) where is a population of individuals ( $V_{s}$ profiles). Each of the individuals is assigned a certain set of information which constitutes its "genotype". In other words, the genotype describes the proposed solution to the problem, and the adaptation function assesses how good this solution is. The fittest individuals (i.e., the ones with the highest fitness values) are chosen to generate offspring. Next, the best individual became "father" of the next generation. Mutation operators allow good genes (that have never appeared before) to be selected and should also ensure that a potentially good component is not lost during reproduction and crossover operations. The process can stop after a fixed number of generations or when the fitness of an individual reaches a certain previously-fixed value (Ramillien 2001, Dal Moro et al. 2007).

\section{METHODOLOGY}

\subsection{Field works}

The study was made in two limestone quarries (Deposit 1 - Strzelce Opolskie quarry and Deposit 2 - Sadowa Góra quarry). The geometrical parameters of cracks were measured using geological compass. The P.A.S.I. equipment was used for seismic measurements. The seismic profiles were oriented at 30 degrees to cardinal points of the compass. Twelve geophones were placed along each profile at 2-meter (Deposit 1) and 3-meter (Deposit 2) spacing. To generate seismic waves, an eight kilogram hammer and metal plate were used. The first break times of $P$ and $S$ waves were read from recorded seismograms and, on this basis, seismic wave velocities were calculated. 


\subsection{Data processing}

The seismic traces obtained during field surveys were analysed in WinMASW software, created by Eliosoft. The data is prepared for the phase velocity spectrum calculation. Traces are cut and only the useful signal is put to $p-\tau$ and $\mathrm{FT}$ transform. Before these transformations range of frequency and range of phase velocities had been set. The frequency range was from 1 to $160 \mathrm{~Hz}$ and the phase velocity range was changing from 20 to $1600 \mathrm{~m} / \mathrm{s}$ or more (it depends on dispersion curve size). The result was the phase velocity spectrum with distinguished dispersion curve or curves - it depended on the number of modes observed.

The next step was to create a model of the dispersion curves. A priori data from the refraction seismic were used to find approximation of $S$-wave velocity and thickness of layers. The WinMASW software allows to calculate a dispersion curve model. This procedure enables obtaining the initial model (reference model) during the inversion process.

An appropriate fitted model with picked Rayleigh wave modes is used for the inversion procedure. After the inversion using Genetic Algorithm application, the final models are obtained. The results consist of the $S$-wave profiles - the best one and the average one (Fig. 3), the misfit changes in each generation and geotechnical parameters.
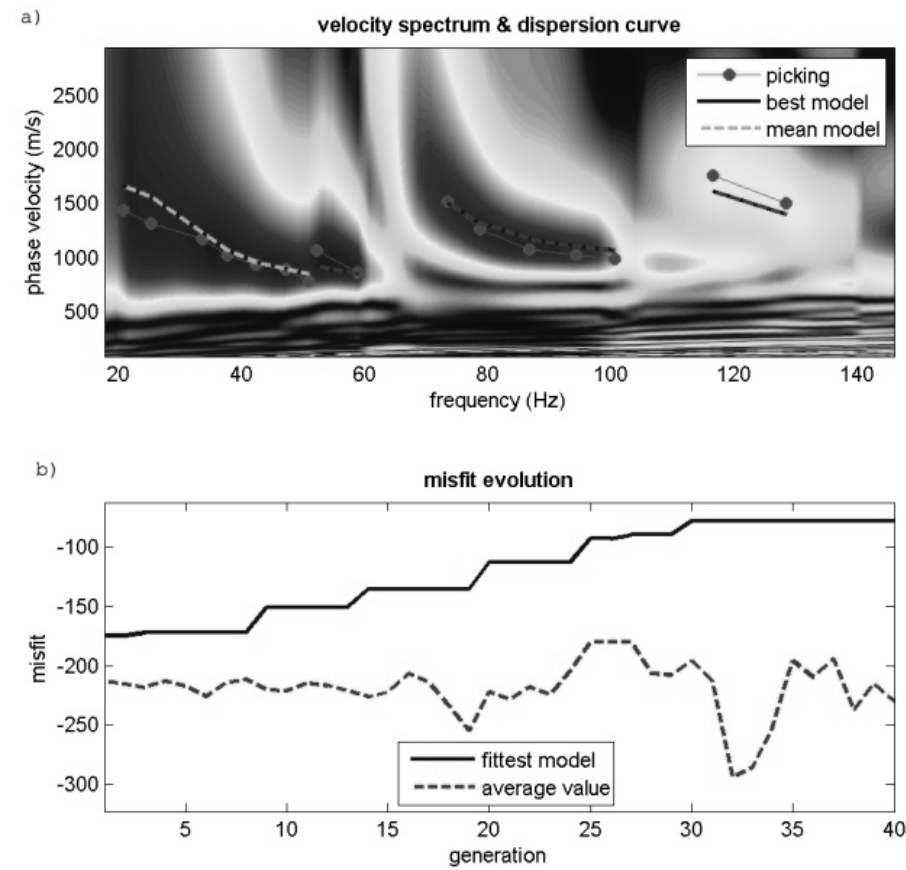

Fig. 3. Continued on next page. 


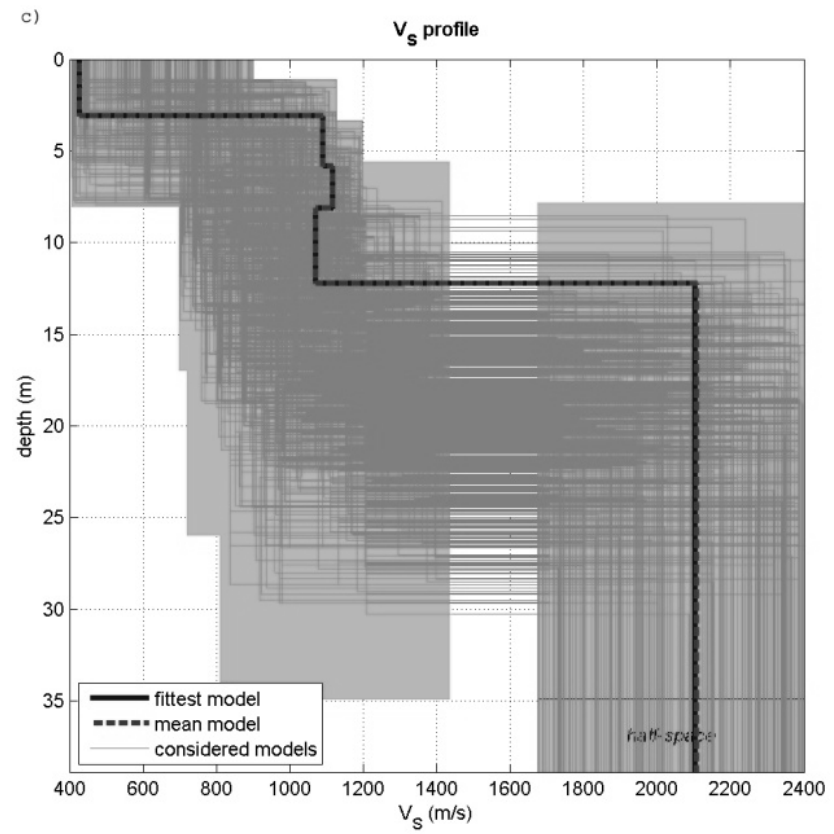

dataset: 0stcut1.sgy

dispersion curve: masw0st2.cdp

Vs30 (best model): $1245 \mathrm{~m} / \mathrm{s}$

Vs30 (mean model): $1246 \mathrm{~m} / \mathrm{s}$

Fig. 3. An example of the result for data from Sadowa Góra - azimuth of $30 \mathrm{deg}$. The figure consists of phase velocity spectrum (a), misfit evaluation (b), and considered models of $S$-waves profiles with the best and mean models (c).

All data were inverted using the 2-layered model as the initial model. The first layer was a low-velocity zone (cracked limestone) with velocities between 300 and $600 \mathrm{~m} / \mathrm{s}$. The second layer was assumed as consolidated limestone with relative higher $S$-wave velocity range: $1000-2000 \mathrm{~m} / \mathrm{s}$. However, only shallow data were taken into account in the present paper. Due to a small number of geophones, relative short geophones spacing and not far offset, it is assumed that the second layer is always biased.

\section{RESULTS AND DISSCUSION}

In the investigated deposits, azimuth distributions of seismic wave velocity are characterised by the occurrence of velocity maxima at specific directions. The three predominant fracture orientations were observed for Deposit 1: A $\left(50^{\circ}-60^{\circ}\right), \mathrm{B}\left(70^{\circ}-90^{\circ}\right)$, and $\mathrm{C}\left(160^{\circ}-180^{\circ}\right)$ and for Deposit 2 : $\mathrm{A}^{\prime}\left(70^{\circ}-90^{\circ}\right)$, $\mathrm{B}^{\prime}\left(110^{\circ}-150^{\circ}\right)$, and $\mathrm{C}^{\prime}\left(160^{\circ}-180^{\circ}\right)$. The results of $P$ - and $S$-wave velocities 
from the seismic refraction (RFR) method (Stan-Kłeczek et al. 2012) and $S$-wave velocity from MASW technique are presented in Table 1.

Table 1

The $P$ - and $S$-wave velocities from RFR

and the result of $S$-wave velocity from MASW

\begin{tabular}{|c|c|c|c|c|c|c|c|c|c|}
\hline \multicolumn{5}{|c|}{ Deposit 1 - Strzelce Opolskie } & \multicolumn{5}{|c|}{ Deposit 2 - Sadowa Góra } \\
\hline \multirow[b]{2}{*}{ Azimuth } & \multicolumn{2}{|c|}{ RFR data* } & \multicolumn{2}{|c|}{ MASW data } & \multirow[b]{2}{*}{ Azimuth } & \multicolumn{2}{|c|}{ RFR data* } & \multicolumn{2}{|c|}{ MASW data } \\
\hline & $\begin{array}{c}V_{p} \\
{[\mathrm{~m} / \mathrm{s}]}\end{array}$ & $\begin{array}{c}V_{s} \\
{[\mathrm{~m} / \mathrm{s}]}\end{array}$ & $\begin{array}{c}V_{s} \\
{[\mathrm{~m} / \mathrm{s}]}\end{array}$ & $\begin{array}{c}\Delta V_{s} \\
{[\mathrm{~m} / \mathrm{s}]}\end{array}$ & & $\begin{array}{c}V_{p} \\
{[\mathrm{~m} / \mathrm{s}]}\end{array}$ & $\begin{array}{c}V_{s} \\
{[\mathrm{~m} / \mathrm{s}]}\end{array}$ & $\begin{array}{c}V_{s} \\
{[\mathrm{~m} / \mathrm{s}]}\end{array}$ & $\begin{array}{c}\Delta V_{s} \\
{[\mathrm{~m} / \mathrm{s}]}\end{array}$ \\
\hline 0 & 2630 & 1100 & 900 & 6 & 0 & 1050 & 367 & 553 & 8 \\
\hline 30 & 2630 & 950 & 815 & 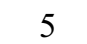 & 30 & 990 & 465 & 469 & $<1$ \\
\hline 60 & 2700 & 830 & 875 & 4 & 60 & 1100 & 396 & 439 & $<1$ \\
\hline 90 & 3125 & 920 & 82 & 12 & 90 & 800 & 346 & 419 & 3 \\
\hline 120 & 2860 & 860 & 698 & 4 & 120 & 930 & 320 & 365 & 1 \\
\hline 150 & 2440 & 830 & 773 & 7 & 15 & 1050 & 340 & - & - \\
\hline 180 & 2630 & 1100 & 900 & 6 & 180 & 1050 & 367 & 553 & 8 \\
\hline 210 & 2630 & 950 & 815 & 5 & 210 & 990 & 465 & 469 & $<1$ \\
\hline 240 & 2700 & 830 & 875 & 4 & 240 & 1100 & 396 & 439 & $<1$ \\
\hline 270 & 3125 & 920 & 825 & 12 & 270 & 800 & 346 & 419 & 3 \\
\hline 300 & 2860 & 860 & 698 & 4 & 300 & 930 & 320 & 365 & 1 \\
\hline 330 & 2440 & 830 & 773 & 7 & 330 & 1050 & 340 & - & - \\
\hline 360 & 2630 & 1100 & 900 & 6 & 360 & 1050 & 367 & 553 & 8 \\
\hline
\end{tabular}

*)RFR data published in Stan-Kleczek et al. (2012)

As it was mentioned, only the result from shallow layer was considered in this study and compared with previous data from both deposits. Moreover, it needs to be highlighted that for some azimuth angle it was difficult to calculate velocities. In Table 1 this is marked as "“-“. There are several reasons why the velocity could not be found; in the most cases, data were bad, without distinguished $P$-arrivals and surface wave waveforms, and they will be repeated in near future. The presented MASW data (Table 1) are $S$-wave velocities obtained for an average model, and standard deviations $\Delta V_{s}$ for each velocity are also added.

In Fig. 4 values from Table 1 are plotted together. Figure 4a shows data from Deposit 1 (Strzelce Opolskie) and Fig. 4b describes velocity changes in Deposit 2 (Sadowa Góra). Standard deviations are not marked because their values are too small. In investigated deposits, azimuth distributions of the seismic $P$-wave velocity are characterised by the occurrence of velocity maxima at specific directions. These directions agree with the measured directions of the main crack systems (Fig. 4). 


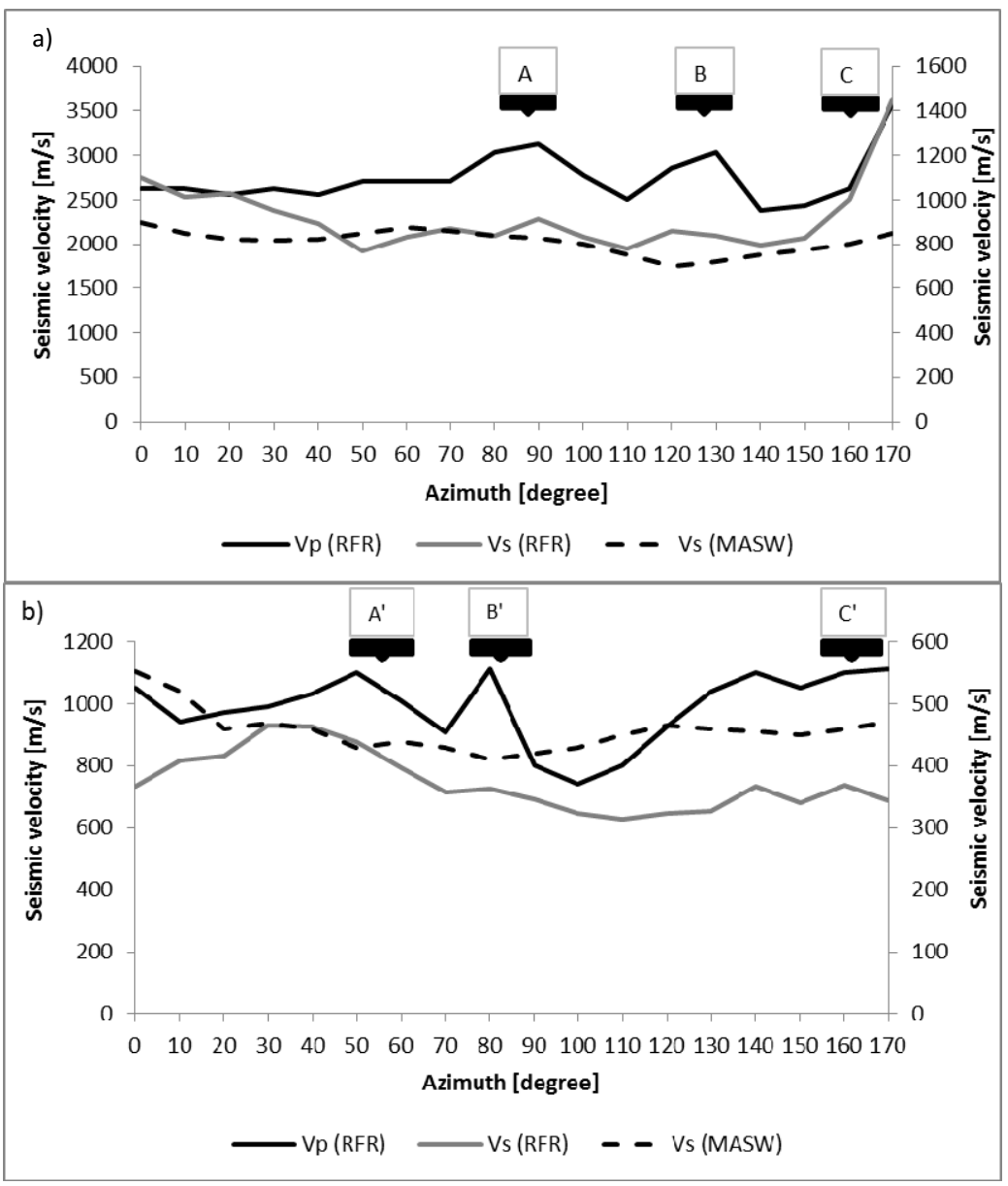

Fig. 4. The comparison of the azimuth of $P$ - and $S$-wave velocity systems: (a) Deposit 1, (b) Deposit 2. A(A'), B(B'), C(C') - main crack systems.

The azimuth distributions of the seismic $S$-wave velocity obtained from refraction and MASW method do not show such a correlation. The velocities obtained from MASW method are smaller than those calculated from the refraction seismic surveys. The values are lower by approximately $4-150 \mathrm{~m} / \mathrm{s}$. The reason of these differences can be found in different approaches to $S$-wave calculations. The survey was carried out using vertical geophones, hence only the vertical component of $S$ waves could be registered. Moreover, values obtained from MASW are average values of $S$-wave velocities. Another reason of these variations is that they can be generated due to the uncertainties occurring during the determination of $S$-wave velocity in both 
methods. The dispersion curve on spectrum is not a thin line but a certain area with high energy amplitudes. Therefore, the marked dispersion curves cannot be precise.

The study of the seismic refraction method shows better results than the MASW method. It may also be associated with methodology of the refraction measurements which were made along radial profiles at 10 degrees. The MASW research was carried out along profiles at $0,30,60,90,120$, and 150 azimuths. The main crack systems were not shown.

\section{CONCLUSION}

The obtained results show that the $S$ wave reflects the major systems of cracks much less than the $P$ wave. This situation could be related to the direction of wave incidence and the vertical geophones applied to the measurement and/or crack-filling water which effects on the directional velocity distributions.

More dense distribution of the MASW survey lines will allow to see anisotropy more precisely and fully utilize all the possibilities of MASW methods.

\section{References}

Anderson, D.L., B. Minster, and D. Cole (1974), The effect of oriented cracks on seismic velocities, J. Geophys. Res. 79, 26, 4011-4015, DOI: 10.1029/ JB079i026p04011.

Barton, N. (2007), Rock Quality, Seismic Velocity, Attenuation and Anisotropy, Taylor \& Francis Group. London.

Bukowska, M., and U. Sanetra (2008), The tests of the conventional triaxial granite and dolomite compression in the aspect of their mechanical properties, Miner. Resour. Manage. 24, 2, 345-358.

Bukowska, M., U. Sanetra, and M. Wadas (2007), The post-peak failure properties and deformational structures of rocks under conventional triaxial compression conditions, Archiv. Min. Sci. 52, 3, 297-310.

Çaylak, Ç., and İ. Kaftan (2014), Determination of near-surface structures from multi-channel surface wave data using multi-layer perceptron neural network (MLPNN) algorithm, Acta Geophys. 62, 6, 1310-1327, DOI: 10.2478/ s11600-014-0207-8.

Czarakcziewa, A. (1971), Geological documentation of Triassic limestone deposit "STRZELCE OPOLSKIE" in cat. B, $\mathrm{C}_{1}, \mathrm{C}_{2}$, Przedsiębiorstwo Geologiczne, Kraków (in Polish). 
Dal Moro, G., M. Pipan, and P. Gabrielli (2007), Rayleigh wave dispersion curve inversion via genetic algorithms and Marginal Posterior Probability Density estimation, J. Appl. Geophys. 61, 1, 39-55, DOI: 10.1016/j.jappgeo.2006. 04.002 .

Dobróka, M., and J. Somogyi Molnár (2012), New petrophysical model describing the pressure dependence of seismic velocity, Acta Geophys. 60, 2, 371-383, DOI: $10.2478 / \mathrm{s} 11600-011-0079-0$.

Foti, S., S. Parolai, D. Albarello, and M. Picozzi (2011), Application of surfacewave methods for seismic site characterization, Surv. Geophys. 32, 6, 777825, DOI: 10.1007/s10712-011-9134-2.

Jarzyna, J., M. Bała, and A. Cichy (2010), Elastic parameters of rocks from well logging in near surface sediments, Acta Geophys. 58, 1, 34-48, DOI: 10.2478/s11600-009-0036-3.

Lai, C.G., and G.J. Rix (1998), Simultaneous inversion of Rayleigh phase velocity and attenuation for near-surface site characterization, Georgia Institute of Technology, School of Civil and Environmental Engineering, Report No. GIT-CEE/GEO-98-2, 258 pp.

Louie, J.N. (2001), Faster, better: shear-wave velocity to 100 meters depth from refraction microtremor arrays, Bull. Seismol. Soc. Am. 91, 2, 347-364, DOI: $10.1785 / 0120000098$.

Nazarian, S., K.H. Stokoe II, and W.R. Hudson (1983), Use of spectral analysis of surface waves method for determination of moduli and thicknesses of pavement systems, Transport. Res. Record 930, 38-45.

Park, C.B., R.D. Miller, and J. Xia (1999), Multichannel analysis of surface waves, Geophysics 64, 3, 800-808, DOI: 10.1190/1.1444590.

Polkowski, M., and M. Grad (2015), Seismic wave velocities in deep sediments in Poland: borehole and refraction data compilation, Acta Geophys. 63, 3, 698-714, DOI: 10.1515/acgeo-2015-0019.

Ramillien, G. (2001), Genetic algorithms for geophysical parameter inversion from altimeter data, Geophys. J. Int. 147, 2, 393-402, DOI: 10.1046/j.0956540x.2001.01543.x.

Stan-Kłeczek, I. (2008), The role of seismic methods in investigation of rock mass, Acta Geophys. 56, 4, 1065-1073, DOI: 10.2478/s11600-008-0052-8.

Stan-Kłeczek, I., and A.F. Idziak (2008), Anisotropy of elastic properties of rock mass induced by cracks, Acta Geodyn.Geomater. 5, 2, 150, 153-159.

Stan-Kłeczek, I., K. Sutkowska, D. Stan, and M. Zolich (2012), The study of the relationship between cracks and seismic parameters of rock, Acta Geodyn. Geomater. 9, 2, 166, 137-142.

Vilhelm, J., V. Rudajev, and R. Živor (2011), Assessment of fracture properties from P-wave velocity distribution. In: A.F. Idziak and R. Dubiel (eds.), Geophysics in Mining and Enviromental Protection, Geoplanet: Earth and 
Planetary Sciences, Vol. 2, Springer, Berlin Heidelberg, 109-116, DOI: 10.1007/978-3-642-19097-1_11.

Xia, J., R.D. Miller, and C.B. Park (1999), Estimation of near-surface shear-wave velocity by inversion of Rayleigh waves, Geophysics 64, 3, 691-700, DOI: 10.1190/1.1444578.

Živor, R., J. Vilhelm, V. Rudajev, and T. Lokajícek (2011), Measurement of P- and S-wave velocities in a rock massif and its use in estimation elastic moduli, Acta Geodyn. Geomat. 8, 2, 157-167.

Received 20 August 2015 Received in revised form 10 December 2015

Accepted 3 February 2016 